\title{
Prevalence and Predictors of Depression Among Eritrean Refugees in Ethiopia: A Cross-Sectional Survey
}

\author{
Samuel Mobae Berhe' \\ Telake Azale ${ }^{2}$ \\ Tolesa Fanta (D) \\ Wubit Demeke' \\ Amare Minyihun (D) $^{3}$
}

'Amanuel Mental Specialized Hospital, Addis Ababa, Ethiopia; ${ }^{2}$ Department of Health Education and Behavioral Sciences, University of Gondar, Gondar, Ethiopia; ${ }^{3}$ Department of Health Systems and Policy, University of Gondar, Gondar, Ethiopia

Correspondence: Telake Azale Department of Health Education and Behavioral Sciences, University of Gondar, Gondar, Ethiopia

Email atelake07@gmail.comc
Background: Depressive disorders place an enormous burden on society and ranked fourth in the global disease burden accounting for $4.4 \%$ of the total disability-adjusted life years and $11.9 \%$ of total years lived with disability. Depression is associated with high level of morbidity and it is the most common contributor to suicide. Refugees have higher rates of mental disorders, in particular depression than those usually found in the non-war affected general population. There is a dearth of evidence in Ethiopia regarding the mental health of refugees.

Objective: This study aimed to assess the prevalence of depression and associated factors among Eritrean refugees in Tigray North Ethiopia.

Methods: A cross-sectional study was conducted at Maiayni refugee camp. A total of 800 participants were interviewed using systematic random sampling method. Pretested, structured and interviewer administered questionnaire that included socio demographic, clinical, behavioral, Harvard trauma questionnaire, and the patient health questionnaire (PHQ-9) was used. Descriptive statistics and binary logistic regression analyses were carried out.

Results: With 786 (98.3\%) of response rate, the prevalence of depression was found to be $37.8 \%, 95 \%$ confidence interval $(34.2,41.2)$. The odds of depression was higher in females $[(\mathrm{AOR}=8.9295 \% \mathrm{CI}(5.21,15.25)]$, older age $[(\mathrm{AOR}=2.7295 \% \mathrm{CI}(1.03-7.16)]$, those who never attended school $[(\mathrm{AOR}=3.09$ 95\% CI (1.16-8.24)], among the unemployed $[(\mathrm{AOR}=2.3695 \% \mathrm{CI}(1.16-4.83)]$, those with poor social support [(AOR=8.67 95\% CI (4.24-17.77)], past psychiatric history [(AOR=4.76 95\% CI (1.94-11.67)], family history of a psychiatric disorder [(AOR=3.96 95\% CI (1.93-8.13)], those who were using substances [(AOR=4.08 95\% CI (2.51-6.65)], and among those who stayed for longer than a year at the camp [(AOR=4.18 95\% CI (2.47-7.08))].

Conclusion: The study revealed that depression is a major mental health and public health problem among Eritrean refugees in Ethiopia. Several socio-demographic, psychosocial, behavioral and clinical factors were significant predictors of depression among the study participants. Mental health service provision for the refugees needs to be part of the support. Keywords: Eritrean refugee, depression, PHQ-9, trauma, internally displaced, Ethiopia

\section{Introduction}

The estimated number of depression suffering from depression exceeded 322 million globally. ${ }^{1}$ The prevalence of depression varies from region to region and ranges from $2.6 \%$ in western Pacific to $60 \%$ in Africa. In Ethiopia, the pooled prevalence reported by a systematic review is $11 \%{ }^{2}$

Studies about the global burden of diseases showed that unipolar depressive disorders place an enormous burden on society and ranked as the fourth leading 
cause of burden among all diseases accounting for $4.4 \%$ of the total DALYS and $11.9 \%$ of total YLDS. By the year 2020, if current trends for demographic and epidemiological transition continue, the burden of depressive disorders will increase to $5.7 \%$ of the total burden of disease, becoming the second leading cause of DALYS lost. ${ }^{3,4}$

Forced displacement (also forced migration) is an involuntary or coerced movement of a person or people away from their home or home region. The UNHCR defines "forced displacement" as follows: displaced "as a result of persecution, conflict, generalized violence or human rights violations". 5 According to UNESCO, armed conflict and political issues are the most common causes of forced displacement and migration outflows from Latin America, Africa, and Asia. About 1\% of the world's population or 65 million people live in forced displacement and extreme poverty out of which two-third are fleeing conflict and violence. ${ }^{5}$ Several studies indicated that adults, adolescents and children who were in refuges experienced high levels of mental health problems with anxiety, depression and post-traumatic stress disorder the most commonly reported. ${ }^{6}$ Among internally displaced persons and refugees, the reported prevalence ranged from $3 \%$ to $88 \%$ for post-traumatic stress disorder, $5 \%$ to $80 \%$ for depression, and $1 \%$ to $81 \%$ for anxiety disorders with large variation. ${ }^{7}$ Evidence from populationbased studies among refugees suggests that refugees have higher depression rates than those found in the non-war affected general population., 8

The increased vulnerability of refugees to depression has been linked to both pre-migration experiences, such as exposure to war trauma, ${ }^{10,11}$ and post-migration stressful situations refugees often face in a new country, including separation from family, difficulties with asylum procedure or even detention, unemployment, inadequate housing, and issues related to acculturation. ${ }^{12,13}$

Studies conducted in refugee camps have reported high level of distress and psychiatric morbidity in asylum seekers and refugees with depression rates from $9.8 \%$ to $67.4 \%{ }^{14-16}$

Exposure to chronic civil conflict that is characterized by widespread human suffering, and massive displacement is associated with high rates of major depressive disorder (MDD) of between 39\% and 97\%. ${ }^{17-23}$

Unemployment, poverty, violence, migration, old age, and low education are the most frequently reported risk factors for depression. ${ }^{24}$

The prevalence of depressive disorders among refugees varies from region to region with the lowest being $2.3 \%$ among Southeast Asian refugees who settled in Canada ${ }^{25}$ and the highest $80 \%$ among Cambodian refugees in the USA. $^{26}$

In another meta-analysis of 181 surveys that comprised 81,866 refugees from 40 countries, the pooled prevalence rate of depression was $30.8 \% .{ }^{11}$ In this study, cumulative exposure to traumatic events, shorter time since exposure to trauma, torture, and residence were the predictors of depression.

A study among the Bhutanese Refugees in the United States reported $21 \%$ prevalence rate of depression. Women had a significantly higher prevalence of depression than men and symptoms of depression were significantly associated with symptoms of PTSD, anxiety, and suicidal ideation. Refugees who had experienced four or more traumatic events were at higher odds of symptoms of depression. On the other hand, refugees with perceived low social support were more likely to have symptoms of depression. ${ }^{27}$

A systematic review on refugees from Iraq, who settled in Western countries, revealed depression rates ranging from $28.3 \%$ to $75 \%{ }^{28}$

A recent study of Syrian refugees in Jordan showed that the prevalence rate of depression was $29.5 \%$. Depression was associated with low income, history of chronic disease before arrival in Jordan, diagnosis of chronic disease in Jordan, and shortage of medications. ${ }^{29}$ Similar studies in African region also reported high rates of depression. For example, in a cross-sectional study among internally displaced people in Northern Uganda, the prevalence of depression was $67 \%$ with women reporting significantly higher rate $(78 \%$ women versus $51.4 \%$ men). Factors significantly associated with depression were rape or sexual abuse, unnatural death of family/friend, murder of stranger or strangers and being tortured or beaten. ${ }^{23}$

Another cross-sectional survey among internally displaced persons and refugees in Juba, Southern Sudan, found that the prevalence of depression was $49.9 \%$ of which $58.7 \%$ were women and $40.9 \%$ men. Among other things, forced separation from family, chronic health issues, and prosecution were associated with depression. ${ }^{30}$

The prevalence of depression among Somali refugees in Ethiopia was reported to be $38.3 \%$. Adverse experiences such as witnessing the murder of close family members, not having a shelter, and marital separation were important predictors of depression. ${ }^{31}$

Mental health of refugees has been attracting research attention globally. Identifying mental health problems in low-income countries such as Ethiopia where conflict and the resulting forced displacement are very high is crucial 
for designing intervention. However, evidence on the burden of mental disorders among refugees in those countries is scarce. Therefore, this study will serve as a baseline information to alert program planners to help them put in place screening program and appropriate mental health intervention for refugees in Ethiopia.

\section{Materials and Methods Study Design and Period}

This cross-sectional study was conducted in a special population, refugees from May to June 2016.

\section{Study Area}

Maiayni Refugee Camp is one of the four official refugee camps in Tigray region of Ethiopia. It is located in the north eastern part of Ethiopia $949 \mathrm{~km}$ far from Addis Ababa. The camp was established in 2008 by UNHCR and ARRA, and hosts a total of 24,399 refugees and 7000 households. $^{32}$

Maiayni health center has one psychiatric nurse and two clinical psychologists. It has three adult and one pediatric out-patient departments, and in-patient treatment services segregated for males and females. Most basic services are provided in the camps, including food, shelter, basic medical care, water and sanitation. JRS programs attempt to combat the endless tedium of camp life through provision of recreational activities such as sports, music, theatre and dance.

\section{Sample Size Determination and Sampling Procedure}

A sample of 800 adult refugees were selected taking the assumption of proportion (p) $38.3 \%$ from a previous study, ${ }^{31} 95 \%$ confidence level, $5 \%$ margin of error, and a design effect of 2 .

A multistage sampling technique was employed. At stage one from the four camps one camp was selected randomly using lottery method. At the selected camp, there were five zones and individual households in the five zones were selected using a systematic sampling technique after identifying an initial starting household by use of a random number. Proportional to size allocation of the sample to the selected five zones was done. The house numbers we used as a sampling frame were given by the UNHCR. The interval (K) was calculated by dividing the number of households by the sample size allocated to the specific zone and was found to be eight. The data collectors then visited every eighth household. In case there were more than one eligible adult in a household, one was randomly selected for interview.

\section{Measures}

Depression was measured using the Patient Health Questionnaire (PHQ-9). A score of 5 or more in the PHQ9 was considered probable depression. The PHQ-9 has been used among migrant population ${ }^{33}$ and validated in Ethiopia. ${ }^{34}$ Reliability coefficient Cronbach's $\alpha$ in our study for the PHQ-9 was 0.89 showing good internal consistency of the items. This instrument is validated in Ethiopia. ${ }^{35-37}$

Social support was assessed using the Oslo-3 Social support scale (OSSS-3). The level of support was categorized as poor support, ${ }^{8-12,38}$ intermediate support ${ }^{13,39,40}$ and strong support. ${ }^{14,15,39}$ The OSSS measures three aspects of social support including number of persons close to the individual that he or she can rely on; the value that others give to the individual or their concern about him or her; and ease of getting help from family, friends, or neighbors if needed. ${ }^{41}$ The exposure to traumatic events was assessed using a slightly adapted version by Mollica et al of the original Harvard trauma questionnaire (HTQ). ${ }^{35,42}$ This consisted of 16 questions on lifetime exposure to traumatic events with a 'yes/no 'response. Reliability coefficient Cronbach's $\alpha$ in our study for the HTQ was 0.72 showing good internal consistency of the items.

\section{Data Collection}

The data were collected by using structured, pretested and interviewer administered questionnaire. The questionnaire was translated and delivered in Tigrigna, the main language of Eritrean refugees at Tigray refugee camps. Before data collection, four data collectors and one supervisor with bachelor degree were recruited and trained for two days. The data collectors were psychiatric nurses working in government health facilities around the refugee camps. The questionnaire was pretested on 40 individuals at a nearby refugee camp.

The data were collected privately in front of the shelters. The data collection process was supervised on a daily basis by the investigators and daily meetings were held to discuss on problems faced and find solutions. Data collectors had to visit twice the households with the missing respondents at the initial visit before they decided nonresponse and use the next household. The collected data were reviewed and checked for completeness before data entry. The incomplete questionnaires were discarded. 


\section{Data Processing and Analysis}

Data were checked, coded, and entered to EPI-info version 7 and exported to SPSS-20 for analysis. Binary logistic regression analyses with odds ratio (OR) and $95 \%$ confidence interval (CI) were computed. Statistical significance of the results was tested using the $\mathrm{p}$ value less than 0.05 , odds ratio and $95 \%$ confidence interval.

\section{Ethical Consideration}

An ethical clearance was obtained from the Institutional Review Board of University of Gondar. Formal permission was obtained from the management bodies of the camp. Informed written consent was obtained from each participant before data collection. Participants were informed about the aims and purpose of the study, the risks and benefits, the right to refuse or interrupt participation with no consequences. A signed consent form was used to ensure informed consent and clarify that no direct benefit could be expected from participating in the study.

Confidentiality of respondents was maintained by using anonymous data collection tool. The data collectors advised individuals with suicide to consult the psychiatric professionals providing service for the refugees.

\section{Results}

This survey recruited 800 individuals out of which 786 (98.3\%) responded to the interview. Ten questionnaires were found to be incomplete and excluded from the analysis. Four individuals were not found at home on three consecutive visits and registered as non-response.

\section{Socio-Demographic Characteristics}

Out of the 786 respondents 495 (63.0\%) were men. About two-third 548 (69.7\%) of respondents were between 25 and 44 years of age. The median age of respondents was 30 years. About three-quarters, 589 (74.9\%) of the respondents were Orthodox Christians by religion. Regarding marital status $345(43.9 \%)$ of the respondents were married. Among the study participants about two-third, 521 (66.3\%) had attended secondary school and above (Table 1).

\section{Behavioral and Psychosocial Characteristics of Respondents}

Nearly half, 358 (45.5\%) of the respondents were drinking alcohol currently. Respondents who were smoking tobacco currently were $228(29.0 \%)$.
About half, 414 (52.7\%) of the respondents had intermediate social support. Among the total respondents, about two-third (546 (69.5\%)) had spent more than 1 year at the camp. About half (403 (51.3\%)) of respondents currently had no family with them. Among the respondents, $59(7.5 \%)$ had history of previous psychiatric illness and $79(10.1 \%)$ had family history psychiatric illness.

\section{Exposure to Trauma}

Respondents who had ever directly experienced a combat situation were 343 (43.6\%), who had witnessed murder of family or friends were $141(17.9 \%)$, reported witnessing of unnatural death of family were $209(26.6 \%)$, reported forced isolation from others were 398 (50.6\%), reported forced to accept thoughts of others were $564(71.8 \%)$ and reported imprisonment were 274 (34.9\%). Social deprivation is evidenced by the fact that about half $(50.9 \%)$ of the respondents had ever lacked food or water and 390 $(49.6 \%)$ reported lack of house or shelter. Respondents who had been seriously ill without access to medical care were 142 (18.1\%).

More men experienced individual traumatic events than women and have reported slightly higher exposure to 8 or more of the 16 traumatic events included in the questionnaire ( $20 \%$ in women compared to $22.1 \%$ in men) (Table 2).

\section{Prevalence of Depression}

Considering five as a cutoff point, 297 (37.8\%) of the respondents with 95\% confidence interval between (34.2-41.2) had probable depression with more women than men $(56.0 \%$ versus $27.1 \%$ ) scoring five or more in the PHQ-9. (See Supplementary document)

\section{Factors Associated with Depression}

Bivariate analyses were done to examine the association between depression among refugees and each of the variables. Among the factors age, sex, educational status, occupation, displacement history, social support, respondent's and family history of psychiatric illness, current substance use, length of stay at the refugee camp, traumatic event and current presence of family fulfilled the minimum criteria $(\mathrm{P}<0.2)$ for further multivariate logistic analysis. These variables were then entered into a multivariate logistic regression model.

The following factors retained statistical significance with depression at multivariate analysis: older age, female gender, no formal education, unemployment, poor social 
Table I Socio-Demographic Characteristics of Respondents Among Eritrean Refugees at Maiayni Camp, Tigray Region, Ethiopia, $2016(\mathrm{~N}=786)$

\begin{tabular}{|c|c|c|}
\hline Characteristics & Number & Percent \\
\hline \multicolumn{3}{|l|}{ Age, years } \\
\hline$\leq 24$ & 182 & 23.2 \\
\hline $25-44$ & 548 & 69.7 \\
\hline$\geq 45$ & 56 & 7.1 \\
\hline \multicolumn{3}{|l|}{ Sex } \\
\hline Male & 495 & 63.0 \\
\hline Female & 291 & 37.0 \\
\hline \multicolumn{3}{|l|}{ Marital status } \\
\hline Never Married & 331 & 42.1 \\
\hline Married & 345 & 43.9 \\
\hline Divorced & 85 & 10.8 \\
\hline Separated & 25 & 3.2 \\
\hline \multicolumn{3}{|l|}{ Religion } \\
\hline Muslim & 119 & 15.1 \\
\hline Orthodox & 589 & 74.9 \\
\hline Catholic, Protestant and Others & 78 & 9.9 \\
\hline \multicolumn{3}{|l|}{ Ethnicity } \\
\hline Tigre & 22 & 2.8 \\
\hline Tigrigna & 670 & 85.2 \\
\hline Others & 94 & 12.0 \\
\hline \multicolumn{3}{|l|}{ Educational status } \\
\hline Never attend school & 76 & 9.7 \\
\hline Primary & 189 & 24.0 \\
\hline Secondary & 431 & 54.8 \\
\hline Diploma and above & 90 & 11.5 \\
\hline \multicolumn{3}{|l|}{ Occupation } \\
\hline Employed & 119 & 15.1 \\
\hline Unemployed & 667 & 84.9 \\
\hline \multicolumn{3}{|l|}{ Length of stay at the camp } \\
\hline$<1$ year & 240 & 30.5 \\
\hline$\geq 1$ year & 546 & 69.5 \\
\hline \multicolumn{3}{|c|}{ Participant's history of psychiatric } \\
\hline \multicolumn{3}{|l|}{ illness } \\
\hline Yes & 59 & 7.5 \\
\hline No & 727 & 92.5 \\
\hline \multicolumn{3}{|c|}{ Family history of psychiatric illness } \\
\hline Yes & 79 & 10.1 \\
\hline No & 707 & 89.9 \\
\hline \multicolumn{3}{|l|}{ Current presence of family } \\
\hline Yes & 383 & 48.7 \\
\hline No & 403 & 51. \\
\hline
\end{tabular}

support, previous history of displacement, respondents' past psychiatric history and family history of psychiatric illness, current substance use, more than 1 year stay at the camp, degree of trauma and current presence of family.

The odds of having depression in individuals 45 years and older was higher $(\mathrm{AOR}=2.72 ; 95 \% \mathrm{CI}(1.03-7.16))$ compared
Table 2 The Frequency Distribution of Exposure to Traumatic Event Among Eritrean Refugees at Maiayni Camp, Tigray Region, Ethiopia, $2016(\mathrm{~N}=786)$

\begin{tabular}{|l|l|l|}
\hline \multirow{2}{*}{ Trauma Events } & \multicolumn{1}{|c|}{ Yes } & \multicolumn{1}{c|}{ No } \\
\cline { 2 - 3 } & \multicolumn{1}{|c|}{ N (\%) } & \multicolumn{1}{c|}{ N (\%) } \\
\hline Lack of food or water & $394(50.1)$ & $392(49.9)$ \\
\hline Unnatural death of family & $209(26.6)$ & $577(73.4)$ \\
\hline Combat situation & $343(43.6)$ & $443(56.4)$ \\
\hline Murder of family /friend & $141(17.9)$ & $645(82.1)$ \\
\hline Very ill without medical care & $142(18.1)$ & $644(81.9)$ \\
\hline Lack of housing or shelter & $390(49.6)$ & $396(50.4)$ \\
\hline Being close to death & $180(22.9)$ & $606(77.1)$ \\
\hline Forced separation from family & $734(93.4)$ & $52(6.6)$ \\
\hline Serious injury & $221(28.1)$ & $565(71.9)$ \\
\hline Tortured or beaten & $164(20.9)$ & $622(79.1)$ \\
\hline Forced isolation from others & $398(50.6)$ & $388(49.4)$ \\
\hline Murder of stranger & $95(12.1)$ & $691(87.9)$ \\
\hline Forced to accept thoughts of others & $564(71.8)$ & $222(28.2)$ \\
\hline Imprisonment & $274(34.9)$ & $512(65.1)$ \\
\hline Being abducted & $30(3.8)$ & $756(96.2)$ \\
\hline Rape & $39(5)$ & $747(95.0)$ \\
\hline
\end{tabular}

to individuals aged less than 25 years. There was very strong association of gender on depression with women over eight times as likely as men to exhibit the symptoms of depression $(\mathrm{AOR}=8.92 ; 95 \% \mathrm{CI}(5.21-15.25))$.

Respondents who never attended school were more likely $(\mathrm{AOR}=3.09 ; 95 \%$ CI $(1.16-8.24))$ to exhibit depression symptoms compared to those who completed diploma and above.

The likelihood of having depression among individuals who were unemployed was higher $(\mathrm{AOR}=2.36$; 95\% CI (1.16-4.83)) compared to individuals who were employed.

Respondents who were forcefully displaced internally and as a refugee previously were more likely $(\mathrm{AOR}=1.94$; 95\% CI (1.17-3.23)) to exhibit depressive symptoms as compared to those who were never displaced from their home.

Respondents who had poor social support were more than eight times as likely as those who had strong social 
support to exhibit the symptoms of depression ( $\mathrm{AOR}=8.67$; 95\% CI (4.24-17.77)).

The likelihood of having depression among individuals who had previous history of psychiatric illness and family history of psychiatric illness were higher (AOR $=4.76 ; 95 \%$ CI (1.94-11.67) and AOR=3.96; 95\% CI (1.93-8.13)) compared to individuals who had no previous history of psychiatric in themselves and their families.

Respondents who currently use substances were more likely $(\mathrm{AOR}=4.08$; 95\% CI (2.51-6.65)) to exhibit depressive symptoms as compared to those currently do not use substance. The likelihood of having depression symptoms among those who lived at the refugee camp for more than 1 year was higher $(\mathrm{AOR}=4.18 ; 95 \% \mathrm{CI}(2.47-7.08)$ ) as compared to those who lived for less than a year.

Respondents who currently have family living with them were more likely $(\mathrm{AOR}=1.58 ; 95 \%$ CI $(1.02-2.47)$ ) to exhibit depression symptoms compared to individuals currently do not have family living with them.

Respondents who had experienced eight or more traumatic events were more likely to have symptoms of depression (AOR=7.87; 95\% CI (4.55-13.61)) (Table 3).

\section{Discussion}

This is the first study to be conducted on mental health among Eritrean refugees in Ethiopia. More than one-third (37.8\%) of the respondents met symptom criteria for depression with $95 \%$ confidence interval $(34.2,41.2)$. This is consistent with many other studies including a study conducted among refugees in Somali region of Ethiopia (38.3\%), Guatemalan refugees in Mexico (38.8\%), and Karenina refugees living in the ThaiBurma border (41.8\%). ${ }^{17,31,43}$

However, it was higher than a study conducted among Ethiopian immigrants and refugees in Toronto (9.8\%) and among Vietnamese refugee in the United States, which was $20 \%{ }^{44,45}$ The psychosocial and economic supports provided to refugees in the high-income countries are better that may be protective against mental illnesses compared to the situation in Ethiopia. The finding that more women than men have symptoms of depression is universal. ${ }^{17,23,43,45-48}$

Women were more than twice more likely to have depressive symptoms compared to male refugees $(56 \%$ vs $27.1 \%$ ). There is a large body of evidence on the higher prevalence of depression in women around the world conducted among refugees. ${ }^{17,23,43,45-48}$
This study revealed that depression was associated with older age, repeated exposure to traumatic events, and longer duration since displacement, low education, unemployment, and poor social support. This finding is consistent with other studies. ${ }^{17-20,23,49,50}$ Moreover, past psychiatric history of respondents and family history of mental illness were significantly associated with depression in this study and a similar study as well. ${ }^{51}$

Exposure to a series of traumatic events was significantly associated with depression as it is also replicated by similar studies conducted elsewhere in Ethiopia, ${ }^{31}$ Mexico, ${ }^{17}$ and South Sudan. ${ }^{30}$ The more frequently refugees are exposed to traumatic events, the more likely that they will experience symptoms of depression. ${ }^{23,46}$

The study showed that there is a strong association between depression and forced and internal displacement. This finding is consistent with the findings of other studies conducted in another part of Ethiopia and Uganda. ${ }^{30,31}$

Refugees who had longer stay in the camp were more likely to have depression. Those respondents who had already been in the shelter were more likely to be depressed compared to those who lived there shorter. This is in accordance with a study done among North Korean refugees in South Korea and Iraqi refugees in Australia. ${ }^{52,53}$

As the first study among Eritrean refugees in Ethiopia, the findings of this study will provide an opportunity for planning mental health service for refugees in Ethiopia. It may serve as a starting point for mental health need assessment for this specific population and integrate mental health service with the primary health care. This may also pave the ground for further research that would enable to identify risk factors for mental health problems so as to reduce exposure to preventable risk factors.

\section{Limitation of the Study}

Our study relied on cross-sectional data, restricting our ability to infer the causal directions underlying the observed associations.

The study was unable to consistently match the gender of interviewer and respondents. As a result, there may have been underreporting of certain sensitive traumatic experiences. In addition, because our sample resided in a single Eritrean refugee community, it may not be representative of the broader population of Eritrean refugees living out of camps in different cities of Ethiopia. Moreover, we used a screening tool to determine the proportion of participants with probable depression not a definite diagnosis of major depressive disorder. 
Table 3 Factors Associated with Depression Among Eritrean Refugees in Tigray Region, Ethiopia, May 2016 (N= 786)

\begin{tabular}{|c|c|c|c|c|c|}
\hline Variables & & Yes, n(\%) & No, $n(\%)$ & COR $95 \% \mathrm{Cl}$ & $\operatorname{AOR}(95 \% \mathrm{Cl})$ \\
\hline \multirow[t]{3}{*}{ Age } & $\leq 24$ & $61(33.5)$ & $121(66.5)$ & 1.00 & 1.00 \\
\hline & $25-44$ & 197(35.9) & $35 I(64.1)$ & $1.11(0.78-1.59)$ & $0.71(0.42-1.21)$ \\
\hline & $\leq 45$ & $39(69.6)$ & $17(30.4)$ & $4.55(2.38-8.69)$ & $2.72(1.03-7.16)^{* *}$ \\
\hline \multirow[t]{2}{*}{ Sex } & Male & $134(27.1)$ & $36 \mid(72.9)$ & 1.00 & 1.00 \\
\hline & Female & $163(56.0)$ & $128(44.0)$ & $3.43(2.53-4.65)$ & $8.92(5.21-\mid 5.25)^{*}$ \\
\hline \multirow[t]{4}{*}{ Educational status } & $\begin{array}{l}\text { Never attend } \\
\text { school }\end{array}$ & $57(75.0)$ & $19(25.0)$ & $\mid 2.88(6 . \mid 4-27.01)$ & $3.09(1.16-8.24)^{* *}$ \\
\hline & Primary & $90(47.6)$ & $99(52.4)$ & $3.90(2.14-7.11)$ & $1.68(0.74-3.81)$ \\
\hline & Secondary & 133(30.9) & $298(69.1)$ & $1.92(1.09-3.37)$ & $0.84(0.40-1.78)$ \\
\hline & $\begin{array}{l}\text { Diploma and } \\
\text { above }\end{array}$ & $17(18.9)$ & $73(81.1)$ & 1.00 & 1.00 \\
\hline \multirow[t]{2}{*}{ Occupation } & Employed & $23(19.3)$ & $96(80.7)$ & 1.00 & 1.00 \\
\hline & Unemployed & $274(41.1)$ & $393(58.9)$ & $2.9 I(1.80-4.7 I)$ & $2.36(1.16-4.83) *$ \\
\hline \multirow[t]{2}{*}{ Displacement history } & Displaced & $253(42.9)$ & $337(57.1)$ & $2.59(1.79-3.77)$ & $1.94(1.17-3.23)^{*}$ \\
\hline & Not displaced & $44(22.4)$ & $152(77.6)$ & 1.00 & 1.00 \\
\hline \multirow[t]{3}{*}{ Social support } & Poor & $172(66.4)$ & $87(33.6)$ & $9.19(5.32-15.89)$ & $8.67(4.24-17.77) * *$ \\
\hline & Intermediate & $105(25.4)$ & $309(74.6)$ & $1.58(0.93-2.69)$ & $2.13(1.06-4.27)^{*}$ \\
\hline & Strong & $20(17.7)$ & $93(82.3)$ & 1.00 & 1.00 \\
\hline \multirow[t]{2}{*}{ History of psychiatric illness } & Yes & $48(81.4)$ & $11(18.6)$ & $8.38(4.27-16.42)$ & $4.76(1.94-11.67)^{* *}$ \\
\hline & No & $249(34.3)$ & $478(65.7)$ & 1.00 & 1.00 \\
\hline \multirow{2}{*}{$\begin{array}{l}\text { Family history of psychiatric } \\
\text { illness }\end{array}$} & Yes & $54(68.4)$ & $25(31.6)$ & $4.12(2.50-6.79)$ & $3.96(1.93-8.13) * *$ \\
\hline & No & $243(34.4)$ & $464(65.6)$ & 1.00 & 1.00 \\
\hline \multirow[t]{2}{*}{ Substance use } & Never used & $80(29.7)$ & $189(70.3)$ & 1.00 & 1.00 \\
\hline & Ever used & $217(42.0)$ & $300(58.0)$ & $1.71(1.25-2.34)$ & $1.67(0.72-3.92)$ \\
\hline \multirow{2}{*}{$\begin{array}{l}\text { Substance use within last } 3 \\
\text { month }\end{array}$} & Never used & $100(31.2)$ & $221(68.8)$ & 1.00 & 1.00 \\
\hline & Ever used & $197(42.4)$ & $268(57.6)$ & $1.63(1.20-2.19)$ & $4.08(2.5 I-6.65)^{* *}$ \\
\hline \multirow{2}{*}{$\begin{array}{l}\text { Length of stay at the refugee } \\
\text { camp }\end{array}$} & $<1$ year & $48(20.0)$ & $192(80.0)$ & 1.00 & 1.00 \\
\hline & $\geq 1$ year & $249(45.6)$ & $297(54.4)$ & $3.35(2.34-4.79)$ & $4.18(2.47-7.08) * *$ \\
\hline \multirow[t]{2}{*}{ Trauma event } & $<8$ & $188(29.6)$ & $448(70.4)$ & 1.00 & 1.00 \\
\hline & $8-16$ & $109(72.7)$ & $4 I(27.3)$ & $6.33(4.26-9.43)$ & $7.87(4.55-13.61)^{* *}$ \\
\hline \multirow[t]{2}{*}{ Current presence of family } & Yes & 184(48.0) & $199(52.0)$ & $2.37(1.77-3.19)$ & $1.58(1.02-2.47)^{*}$ \\
\hline & No & $113(28.0)$ & $290(72.0)$ & 1.00 & 1.00 \\
\hline
\end{tabular}

Notes: Bold fonts indicate that the variables were significantly associated with depression $*$ Statistically significant $(p<0.01)$. **Statistically significant $(p<0.05)$. Abbreviations: $\mathrm{Cl}$, confidence interval; OR, odds ratio (adjusted). 
However, the PHQ-9 has similar symptoms listed in the diagnostic criteria of the Diagnostic and Statistical Manual of Mental Disorders.

\section{Conclusion}

The study revealed a fairly high prevalence of depression episode among refugees. Older age, being female, having no formal education, unemployment, previous history of displacement, poor social support, past psychiatric history and family psychiatric history, current substance use, longer duration of stay at camp, degree of trauma and availability of family were predictors of depression among Eritrean refugees. This study also provides evidence of exposure to traumatic events and the resultant effect this has upon their mental health. Strengthening social support and protection of refugees needs to be given due attention.

\section{Abbreviations}

ARRA, Administration of Refugees and Returnees Affairs; DALYs, disability-adjusted life years; HTQ, Harvard Trauma Questionnaire; IDPs, internally Displaced Persons; JRS, Jesuit Refugee Service; OSSS, Oslo Social Support Scale; PTSD, post-traumatic stress disorder; UNHCR, United Nations Higher Commissioner for Refugees; YLD, years lost with disability.

\section{Data Sharing Statement}

All the collected and analyzed data are included in the document.

\section{Ethics Approval and Consent to Participate}

The research process passed through the ethical steps. The proposal was submitted to the University of Gondar Institutional Review Board and granted approval. The school of medicine, University of Gondar gave the researcher a support letter to the concerned bodies for cooperation. The study participants were made to participate after being informed about the purpose of the study and their rights to refuse or withdraw. The data were collected after obtaining written consent. The data were secured in locked cupboards and password-protected computers.

\section{Consent for Publication}

Not applicable.

\section{Acknowledgments}

The authors would like to acknowledge the University of Gondar for covering the expense necessary to collect the data. We also thank the data collectors, supervisors, and the study participants for their time and genuineness.

\section{Author Contributions}

All authors discussed on the topic of research, the study area, the measurement tools and drafted the proposal. All of the authors translated the data collection tool to local language. All authors went to the site to recruit, train data collectors, and supervise the data collection process. The data were entered by SM. All authors visualized the data and analyzed the data. TA drafted the manuscript. All the rest read and critically commented on the manuscript. All authors approved the final version to be published. Then, they selected the journal and agreed on it. All authors agreed to be accountable for all aspects of the work.

\section{Funding}

The University of Gondar covered the cost for the questionnaire duplication and per diem for supervisors and data collectors.

\section{Disclosure}

The authors declared that they have no competing interests.

\section{References}

1. WHO. Depression and Other Common Mental Disorders: Global Health Estimates. WHO; 2017.

2. Bitew T. Prevalence and risk factors of depression in Ethiopia: a review. Ethiop J Health Sci. 2014;24(2):161-169. doi:10.4314/ejhs.v24i2.9

3. Patel VJ. Mental health in low-and middle-income countries. Br Med Bull. 2007;81(1):81-96.

4. Peltzer K, Naidoo P, Matseke G, et al. Prevalence of psychological distress and associated factors in tuberculosis patients in public primary care clinics in South Africa. BMC Psychiatry. 2012;12 (1):89. doi:10.1186/1471-244X-12-89

5. Refugees, TUNHCF. Figures at a Glance; 2017.

6. von Werthern M, Robjant K, Chui Z, et al. The impact of immigration detention on mental health: a systematic review. $B M C$ Psychiatry. 2018;18(1):382. doi:10.1186/s12888-018-1945-y

7. Morina N, Akhtar A, Barth J, et al. Psychiatric disorders in refugees and internally displaced persons after forced displacement: a systematic review. Front Psychiatry. 2018;9:433. doi:10.3389/ fpsyt.2018.00433

8. Fazel M, Wheeler J, Danesh JJTL. Prevalence of serious mental disorder in 7000 refugees resettled in western countries: a systematic review. Lancet (London, England). 2005;365 (9467):1309-1314. doi:10.1016/S0140-6736(05)61027-6

9. Tempany MJ. What research tells us about the mental health and psychosocial wellbeing of Sudanese refugees: a literature review. Transcultural Psychiatry. 2009;46(2):300-315. 
10. Johnson H, Thompson AJ. The development and maintenance of post-traumatic stress disorder (PTSD) in civilian adult survivors of war trauma and torture: a review. Clin Psychol Rev. 2008;28 (1):36-47. doi:10.1016/j.cpr.2007.01.017

11. Steel Z, Chey T, Silove D, et al. Association of torture and other potentially traumatic events with mental health outcomes among populations exposed to mass conflict and displacement: a systematic review and meta-analysis. JAMA. 2009;302(5):537-549.

12. Porter M, Haslam NJJ. Predisplacement and postdisplacement factors associated with mental health of refugees and internally displaced persons: a meta-analysis. JAMA. 2005;294(5):602-612. doi:10.1001/ jama.294.5.602

13. Robjant K, Hassan R, Katona C, et al. Mental health implications of detaining asylum seekers: systematic review. $\mathrm{Br} J$ Psychiatry. 2009;194(4):306-312. doi:10.1192/bjp.bp.108.053223

14. Teodorescu DS, Heir T, Hauff E, et al. Mental health problems and post-migration stress among multi-traumatized refugees attending outpatient clinics upon resettlement to Norway. Scandinavian J Psychol. 2012;53(4):316-332.

15. Laban CJ, Gernaat HB, Komproe IH, et al. Postmigration living problems and common psychiatric disorders in Iraqi asylum seekers in the Netherlands. J Nerv Mental Dis. 2005;193(12):825-832.

16. Marshall GN, Schell TL, Elliott MN, et al. Mental health of Cambodian refugees 2 decades after resettlement in the United States. JAMA. 2005;294(5):571-579. doi:10.1001/jama.294.5.571

17. Sabin M, Lopes Cardozo B, Nackerud L, et al. Factors associated with poor mental health among Guatemalan refugees living in Mexico 20 years after civil conflict.. JAMA. 2003;290(5):635-642. doi:10.1001/jama.290.5.635

18. Cardozo BL, Bilukha OO, Crawford CAG, et al. Mental health, social functioning, and disability in postwar Afghanistan. JAMA. 2004;292(5):575-584. doi:10.1001/jama.292.5.575

19. Scholte WF, Olff M, Ventevogel P, et al. Mental health symptoms following war and repression in eastern Afghanistan. JAMA. 2004;292(5):585-593. doi:10.1001/jama.292.5.585

20. Vinck P, Pham PN, Stover E, et al. Exposure to war crimes and implications for peace building in northern Uganda. JAMA. 2007;298(5):543-554. doi:10.1001/jama.298.5.543

21. Rasekh Z, Bauer HM, Manos MM, et al. Women's health and human rights in Afghanistan. JAMA. 1998;280(5):449-455. doi:10.1001/ jama.280.5.449

22. Cardozo BL, Bilukha OO, Gotway CA, et al. Report from the CDC: mental health of women in postwar Afghanistan. $J$ Women's Health. 2005;14(4):285-293.

23. Roberts B, Ocaka KF, Browne J, et al. Factors associated with post-traumatic stress disorder and depression amongst internally displaced persons in northern Uganda. BMC Psychiatry. 2008;8(1):38. doi:10.1186/1471-244X-8-38

24. Reedy J. The Mental Health Conditions of Cambodian Refugee Children and Adolescents. The Ohio State University; 2007.

25. Beiser M, Hou FJSS, medicine. Language acquisition, unemployment and depressive disorder among Southeast Asian refugees: a 10-year study. Soc Sci. 2001;53(10):1321-1334. doi:10.1016/s0277-9536(00) 00412-3

26. Carlson EB, Rosser-Hogan R. Cross-cultural response to trauma: a study of traumatic experiences and posttraumatic symptoms in Cambodian refugees. J Traumatic Stress. 1994;7(1):43-58.

27. Vonnahme LA, Lankau EW, Ao T, Shetty S, Cardozo BL. Factors associated with symptoms of depression among Bhutanese refugees in the United States. J Immigrant Minority Health.2015;17 (6):1705-1714.

28. Slewa-Younan S, Uribe Guajardo MG, Heriseanu A, et al. A systematic review of post-traumatic stress disorder and depression amongst Iraqi refugees located in western countries. J Immigrant Minority Health. 2015;17(4):1231-1239. doi:10.1007/s10903-0140046-3
29. Gammouh OS, Al-Smadi AM, Tawalbeh LI, et al. Peer reviewed: chronic diseases, lack of medications, and depression among Syrian refugees in Jordan, 2013-2014. PrevChronic Dis. 2015;2015:12.

30. Roberts B, Damundu EY, Lomoro O, et al. Post-conflict mental health needs: a cross-sectional survey of trauma, depression and associated factors in Juba, Southern Sudan. BMC Psychiatry. 2009;9(1):7. doi:10.1186/1471-244X-9-7

31. Feyera F, Mihretie G, Bedaso A, et al. Prevalence of depression and associated factors among Somali refugee at melkadida camp, southeast Ethiopia: a cross-sectional study. BMC Psychiatry. 2015;15 (1):171.

32. AFFAIRS, A.F.R.A.R. ARRA UDATE. ARRA; 2016.

33. Feyera F, Mihretie G, Bedaso A, et al. Prevalence of depression and associated factors among Somali refugee at melkadida camp, southeast Ethiopia: a cross-sectional study. BMC Psychiatry. 2015;15 (171):7.

34. Gelaye B, Williams MA, Lemma S, et al. Validity of the Patient Health Questionnaire-9 for depression screening and diagnosis in East Africa. Psychiatry Res. 2013;210(2):653-661. doi:10.1016/j. psychres.2013.07.015

35. American Psychiatric Association. Diagnostic and Statistical Manual of Mental Disorders; DSM-III. 1980.

36. Kroenke K, Spitzer RL, Williams JB, et al. The PHQ-9: validity of a brief depression severity measure. J General Int Med. 2001;16 (9):606-613. doi:10.1046/j.1525-1497.2001.016009606.x

37. Akena D, Joska J, Obuku EA, et al. Comparing the accuracy of brief versus long depression screening instruments which have been validated in low and middle income countries: a systematic review. $B M C$ Psychiatry. 2012;12(1):187. doi:10.1186/1471-244X-12-187

38. Edition F. Diagnostic and Statistical Manual of Mental Disorders. Amercian Psychiatric Association; 2013.

39. Ndetei DM, Khasakhala LI, Kuria MW, et al. The prevalence of mental disorders in adults in different level general medical facilities in Kenya: a cross-sectional study. Ann General Psychiatry. 2009;8 (1):1.

40. Edinger GM. Oxford American Handbook of Psychiatry. Clin Nurse Specialist. 2008;23(4):228.

41. Kocalevent RD, Berg L, Beutel ME, et al. Social support in the general population: standardization of the Oslo social support scale (OSSS-3). BMC Psychol. 2018;6(1):31. doi:10.1186/s40359-0180249-9

42. Mollica RF, Caspi-yavin Y, Bollini P, et al. The Harvard Trauma Questionnaire. Validating a cross-cultural instrument for measuring torture, trauma, and posttraumatic stress disorder in Indochinese refugees. J Nerv Ment Dis. 1992;180(2):111-116. doi:10.1097/ 00005053-199202000-00008

43. Cardozo BL, Talley L, Burton A, et al. Karenni refugees living in Thai-Burmese border camps: traumatic experiences, mental health outcomes, and social functioning. Soc Sci Med. 2004;58 (12):2637-2644. doi:10.1016/j.socscimed.2003.09.024

44. Fenta H, Hyman I, Noh S, et al. Determinants of depression among Ethiopian immigrants and refugees in Toronto. $J$ Nerv Mental Dis. 2004;192(5):363-372. doi:10.1097/01.nmd.0000126729.08179.07

45. Buchwald D, Manson SM, Dinges NG, et al. Prevalence of depressive symptoms among established Vietnamese refugees in the United States. J General Int Med. 1993;8(2):76-81. doi:10.1007/ BF02599987

46. Rasmussen A, Crager M, Baser RE, et al. Onset of posttraumatic stress disorder and major depression among refugees and voluntary migrants to the United States. J Traumatic Stress. 2012;25 (6):705-712. doi: $10.1002 /$ jts. 21763

47. Letica-Crepulja M, Salcioglu E, Francisković T, et al. Factors associated with posttraumatic stress disorder and depression in war survivors displaced in Croatia. Croatian Med J. 2011;52(6):709-717. doi:10.3325/cmj.2011.52.709 
48. Gerritsen AA, Bramsen I, Devillé W, et al. Physical and mental health of Afghan, Iranian and Somali asylum seekers and refugees living in the Netherlands. Soc Psychiatry Psychiatric Epidemiol. 2006;41(1):18-26.

49. Marshall C, Wolfe R, Kossmann T, et al. Risk factors for acquisition of methicillin-resistant Staphylococcus aureus (MRSA) by trauma patients in the intensive care unit. $J$ Hosp Infect. 2004;57 (3):245-252. doi:10.1016/j.jhin.2004.03.024

50. Kinyanda E, Woodburn P, Tugumisirize J, et al. Poverty, life events and the risk for depression in Uganda. Soc Psychiatry Psychiatric Epidemiol. 2011;46(1):35-44. doi:10.1007/s00127009-0164-8
51. Mugisha J, Muyinda H, Malamba S, et al. Major depressive disorder seven years after the conflict in northern Uganda: burden, risk factors and impact on outcomes (The Wayo-Nero Study). BMC Psychiatry. 2015;15(1):48. doi:10.1186/s12888-015-0423-z

52. Park K, Cho Y, Yoon I-J, et al. Social inclusion and length of stay as determinants of health among North Korean refugees in South Korea. Int J Public Health. 2009;54(3):175-182. doi:10.1007/s00038-0098048-y

53. Uribe Guajardo MG, Slewa-Younan S, Smith M, et al. Psychological distress is influenced by length of stay in resettled Iraqi refugees in Australia. Int J Ment Health Syst. 2016;10(1):4. doi:10.1186/s13033016-0036-z

\section{Publish your work in this journal}

Psychology Research and Behavior Management is an international, peer-reviewed, open access journal focusing on the science of psychology and its application in behavior management to develop improved outcomes in the clinical, educational, sports and business arenas. Specific topics covered in the journal include: Neuroscience, memory and decision making; Behavior modification and management; Clinical applications; Business and sports performance management; Social and developmental studies; Animal studies. The manuscript management system is completely online and includes a very quick and fair peer-review system, which is all easy to use. Visit http://www. dovepress.com/testimonials.php to read real quotes from published authors. 